\title{
Effect of pharmacological doses of ascorbic acid on the hepatic microsomal haemoproteins in the guinea-pig
}

\author{
BY JUDITH L. SUTTON, ${ }^{*}$ T. K. BASU $\dagger$ \\ AND J.W. T. DICKERSON \\ Division of Nutrition and Food Science, Department of Biochemistry, \\ University of Surrey, Guildford GU2 $5 X H$, Surrey
}

(Received 8 July 1982-Accepted 20 July 1982)

1. Ascorbic acid deficiency results in a reduction in the activity of the hepatic mixed function oxidase systems in the guinea-pig. In this study, male Dunkin-Hartley guinea-pigs were given $0,50,100,200$ or $300 \mathrm{mg}$ ascorbic acid/d in two equal doses in buffered sucrose solution $(200 \mathrm{~g} / 1)$ for $4 \mathrm{~d}$. Controls received an equal volume of sucrose solution.

2. A dose of $50 \mathrm{mg}$ ascorbic acid/d resulted in a significant rise in the specific activities of both cytochromes P-450 and $b_{5}$. At doses of 200 and $300 \mathrm{mg}$ ascorbic acid/d the concentration of both haemoproteins was significantly lower than the control values. These effects were mirrored by total microsomal haem concentration.

3. These results suggest that when given in large doses, ascorbic acid ceases to act simply as a vitamin and should be considered a drug competing for substrates and cofactors with co-administered drugs and endogenous substrates such as cholesterol.

Many arguments have been advanced in favour of the use of large doses of ascorbic acid, both prophylactically and therapeutically. These are based on the results of various studies, which suggest that humans and animals who undergo biochemical stress or body malfunction have reduced ascorbic acid concentrations in plasma and leucocytes (Rinehart et al. 1936; Kakar et al. 1975; Wilson, 1975) and also that high concentrations of ascorbic acid are found in those tissues concerned with response to biochemical stress (Wilson, 1975). In addition, animals known to synthesize their own ascorbic acid, e.g. the rat, have been reported to increase their synthesis ten-fold in response to certain drugs (Conney et al. 1961; Boyd \& Taylor, 1969).

In the past, these arguments have been countered by claims that ascorbic acid is toxic in large quantities through effects on oxalate and uric acid excretion (for example, Lamden \& Chrystowski, 1954; Briggs et al. 1973; Stein et al. 1976). Many of these claims are now considered doubtful (Mitch et al. 1981; Schmidt et al. 1981).

Ascorbic acid deficiency results in diminution of the mixed function oxidase activity of the liver of guinea-pigs, with effects on cytochromes P-450 and $b_{5}$, cytochrome c reductase (EC 1.6.99.3) (Leber et al. 1969; Zannoni et al. 1972; Degkwitz \& Kim, 1973) and the rate of hydroxylation and demethylation of substrates (Kato et al. 1969; Zannoni et al. 1972).

The study reported here was designed to investigate the hitherto neglected effects of high doses of ascorbic acid on the hepatic drug metabolizing system of the guinea-pig. This species, like man and a few other mammals, is unable to synthesize ascorbic acid.

The recommended daily intake of the vitamin for the guinea-pig is $20-50 \mathrm{mg} / \mathrm{kg}$ body-weight ((US) National Research Council, 1978). A range of doses (0-300 mg/d) was chosen, following extrapolation from the high doses recommended by some authors (Pauling, 1970; Stone, 1972), taking into account the fact that the absorptive capacity of

Present addresses: * Department of Biochemistry, The Medical School, Guy's Hospital, London SE1 9RT.

$\dagger$ Foods and Nutrition Division, Faculty of Home Economics, The University of Alberta, Edmonton, Canada. 
the guinea-pig is different from man's and that the plasma half-life of ascorbic acid is approximately $4 \mathrm{~d}$, compared with $16 \mathrm{~d}$ in man (Norkus \& Rosso, 1975). On the basis of this, a daily dose of $300 \mathrm{mg}$ for a guinea-pig is equivalent to approximately $4.5 \mathrm{~g} / \mathrm{d}$ for a $70 \mathrm{~kg}$ man. Hence, the effects of ascorbic acid on hepatic drug metabolism reported in this paper are in some ways representative of a situation which might occur in man.

\section{METHODS}

Male Dunkin-Hartley guinea-pigs, weighing approximately $300 \mathrm{~g}$, and maintained on a stock diet (FDl pellets, Labsure Ltd) plus water ad lib., were divided into groups on a paired-weight basis following a period of equilibration in metabolism cages. There were five groups in all, and they received $0,50,100,200$ or $300 \mathrm{mg}$ ascorbic acid/d as two equal doses in buffered sucrose $(200 \mathrm{~g} / 1)$ for four successive days. The control group received an equal volume $(1 \mathrm{ml})$ of sucrose solution. The dosing was performed using a plastic syringe attached to a short dosing needle, the end of which was protected by a length of narrow plastic tubing.

The animals were pair-fed with the control group and killed after $4 \mathrm{~d}$. The livers were quickly removed, chilled, weighed, and homogenized in ice-cold potassium chloride $(11.5 \mathrm{~g} / \mathrm{l})$ in Tris buffer $(20 \mathrm{~mm})$, $\mathrm{pH} 7 \cdot 6$, using a glass Potter-Elvehjem homogenizer with a loose fitting Teflon pestle, to produce a homogenate of $250 \mathrm{~g} / 1 \mathrm{w} / \mathrm{v}$.

Homogenates were centrifuged at $10000 \mathrm{~g}$ for $20 \mathrm{~min}$ at $4^{\circ}$. Portions of the supernatant fraction were centrifuged at $105000 \mathrm{~g}$ for $1 \mathrm{~h}$ and the microsomal pellet retained and resuspended in the original volume of buffer.

Washed microsomes were produced by a second $105000 \mathrm{~g}$ centrifugation of the resuspended pellet. The cytochrome P-450 content of the microsomes was determined from the carbon monoxide difference spectra of dithionate-reduced samples, using an extinction coefficient between 450 and $490 \mathrm{~nm}$ of $91 / \mathrm{cm}$ per $\mathrm{mm}$ (Omura \& Sato, 1964). The cytochrome $b_{5}$ content of microsomes was calculated from the difference spectrum between $\mathrm{NADH}$-reduced and oxidized samples, using an extinction coefficient increment between 424 and $409 \mathrm{~nm}$ of $185 / \mathrm{cm}$ per mM (Ernste et al. 1962). The haem content of the washed microsomal fraction and the total homogenate was determined by the method of Schenkman et al. (1973) and the protein content of the fractions used was determined by the method of Lowry et al. (1951).

The statistical significance of differences between values for experimental and control values was tested with a paired Student's $t$ test.

\section{RESULTS}

The dose response relationships of ascorbic acid with respect to the microsomal haemoproteins are shown in Table 1 and Figs. 1 and 2 . A daily dose of $50 \mathrm{mg}$ ascorbic acid resulted in a statistically significant $(P<0.05)$ increase in the specific activities of both cytochromes $\mathrm{P}-450$ and $b_{5}$. This effect was maintained with a dose of $100 \mathrm{mg} / \mathrm{d}$ in the instance of cytochrome $\mathrm{b}_{5}$, but cytochrome P-450 concentration returned to control values with this amount of the vitamin. A dose of $200 \mathrm{mg} / \mathrm{d}$ resulted in both haemoproteins falling below control values and this depression was further exacerbated by $300 \mathrm{mg} / \mathrm{d}(P<0.001)$.

These effects were mirrored by the total microsomal haem concentration measured in washed microsomes, but not by the haem content of the liver homogenate, which showed no significant change with the amount of ascorbic acid administered. 


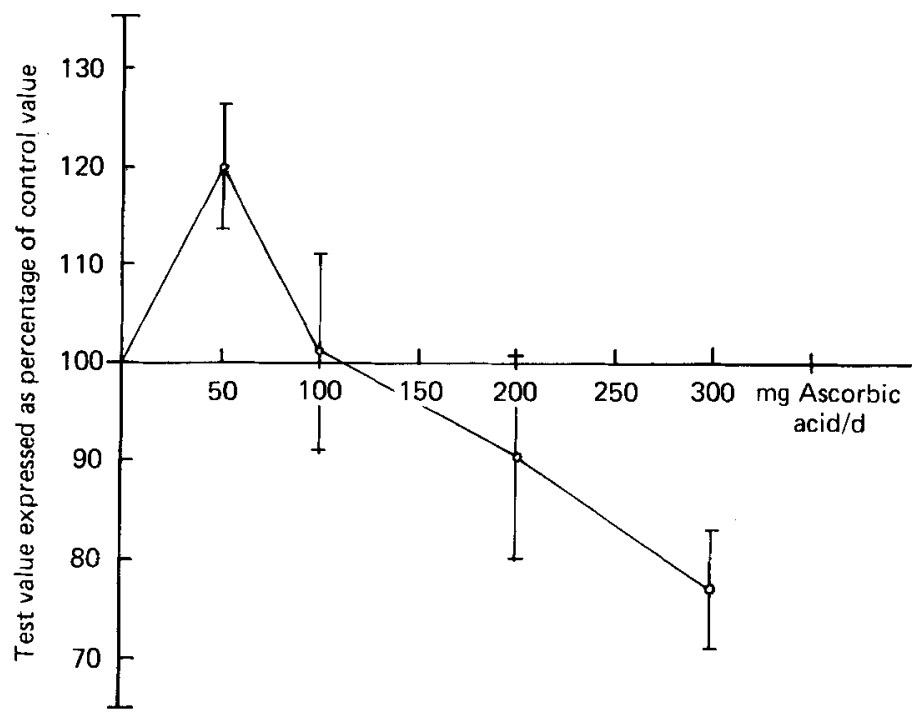

Fig. 1. Effect of administration of different daily doses of ascorbic acid $(0-300 \mathrm{mg} / \mathrm{d})$ over a period of $4 \mathrm{~d}$ on the microsomal cytochrome P-450 content of guinea-pig liver.

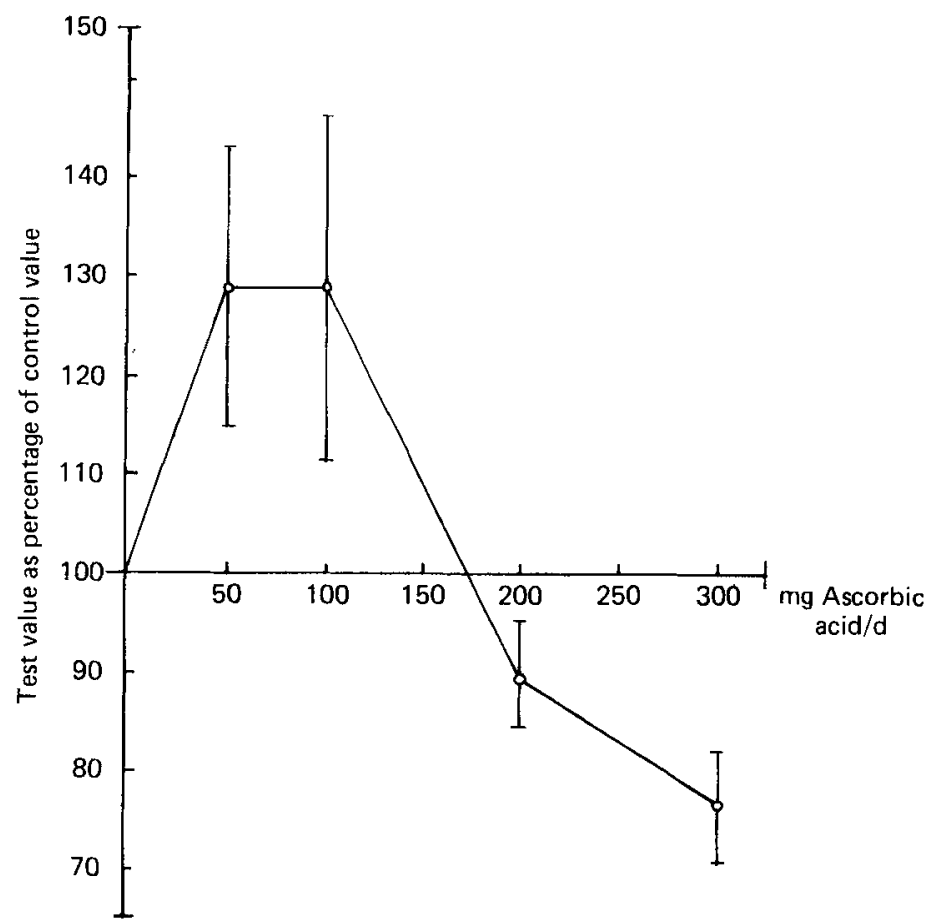

Fig. 2. Effect of administration of different daily doses of ascorbic acid $(0-300 \mathrm{mg} / \mathrm{d})$ over a period of $4 \mathrm{~d}$ on the microsomal cytochrome $\mathrm{b}_{5}$ content of guinea-pig liver. 
Table 1. Effect of different daily doses of ascorbic acid $(0-300 \mathrm{mg} / \mathrm{d})$ on concentrations (nmol/mg protein) of hepatic microsomal cytochromes $P-450$ and $b_{5}$ in the guinea-pig

(Results are expressed as mean values with their standard errors for the number of animals shown. Values in parentheses represent the test value as a percentage of the control value)

\begin{tabular}{|c|c|c|c|c|c|}
\hline \multirow{2}{*}{$\begin{array}{l}\text { Dose of } \\
\text { ascorbic acid } \\
(\mathrm{mg} / \mathrm{d})\end{array}$} & \multirow[b]{2}{*}{$n$} & \multicolumn{2}{|c|}{ Cytochrome $b_{5}$} & \multicolumn{2}{|c|}{ Cytochrome P-450 } \\
\hline & & Mean & SE & Mean & SE \\
\hline 0 & 8 & 0.52 & $0.03(100)$ & 0.88 & $0.06(100)$ \\
\hline 50 & 4 & $0.65^{*}$ & $0.06(68 \pm 16)$ & $1 \cdot 10^{*}$ & $0.09(120 \pm 6)$ \\
\hline 100 & 8 & 0.65 & $0.09(128 \pm 18)$ & 0.9 & $0.05(102 \pm 9)$ \\
\hline 200 & 4 & 0.47 & $0.03(90 \pm 4)$ & 0.75 & $0.06(91 \pm 8)$ \\
\hline 300 & 16 & $0 \cdot 40^{* * *}$ & $0.03(77 \pm 5)$ & $0.67^{* * *}$ & $0.06(78 \pm 6)$ \\
\hline
\end{tabular}

Values were significantly different from the control value: ${ }^{*} P<0.05,{ }^{* *} P<0.001$.

Table 2. Effect of administration of different doses of ascorbic acid on the haem concentration (nmol/mg protein) in different liver fractions of the guinea-pig

(Results are expressed as mean values with their standard errors for the number of animals shown)

\begin{tabular}{|c|c|c|c|c|c|}
\hline \multirow{2}{*}{$\begin{array}{c}\text { Dose of } \\
\text { ascorbic acid } \\
(\mathrm{mg} / \mathrm{d})\end{array}$} & \multirow[b]{2}{*}{$n$} & \multicolumn{2}{|c|}{ Total homogenate } & \multicolumn{2}{|c|}{ Washed microsomes } \\
\hline & & Mean & SE & Mean & SE \\
\hline 0 & 8 & 1.93 & 0.24 & $1 \cdot 19$ & 0.06 \\
\hline 50 & 4 & 1.25 & 0.21 & $1 \cdot 32$ & 0.09 \\
\hline 100 & 8 & 1.61 & $0 \cdot 19$ & $1 \cdot 22$ & 0.02 \\
\hline 200 & 4 & $1 \cdot 76$ & 0.05 & 0.96 & 0.02 \\
\hline 300 & 6 & $1 \cdot 60$ & $0 \cdot 18$ & 0.62 & $0.07^{* * *}$ \\
\hline
\end{tabular}

Value was significantly different from the control value: $* * * P<0.001$.

\section{DISCUSSION}

There appears to be a variation in sensitivity of the two major microsomal haemoproteins to large doses of ascorbic acid, with enhancement of cytochrome P-450 with doses of $50 \mathrm{mg} / \mathrm{d}$ only, whereas enhancement of cytochrome $b_{5}$ activity continued with doses of up to $100 \mathrm{mg} / \mathrm{d}$. These doses are very large for a $300 \mathrm{~g}$ guinea-pig, whose daily requirement to prevent scurvy is only approximately $1-2 \mathrm{mg} / \mathrm{d}$ (Chatterjee, 1967).

Larger doses, of $200 \mathrm{mg} / \mathrm{d}$ or more, resulted in a decrease in the activity of cytochrome P-450, the terminal oxygenase of the mixed function oxidase system, an effect also seen in ascorbic acid deficiency (Leber et al. 1969; Zannoni et al. 1972; Degkwitz \& Kim, 1973). The mechanism of action is not yet clear. However, it seems possible that, whereas ascorbic acid deficiency affects apoprotein synthesis (Rikans et al. 1978), high doses compromise haemoprotein synthesis (Sutton et al. 1982) with a resultant increase in haem synthesis and decrease in haem degradation in an attempt to conserve haem. It is not known whether the haem moiety, the apoprotein moiety or the joining of the two molecules is the point at which the vitamin, either directly or indirectly, has its effect.

Sato \& Zannoni (1974) reported enhanced cytochrome P-450 activity at a dose level of $75 \mathrm{mg} / \mathrm{d}$ in weanling guinea-pigs. Other work from these authors (Sato \& Zannoni, 1976) 
suggests that a correlation exists between hepatic cytochrome P-450 and ascorbic acid concentrations in the $15000 \mathrm{~g}$ supernatant fraction, whereby a ratio of $1: 2$ exists in those tissues which are capable of drug metabolism, such as the liver and adrenals. Following studies involving ferrous ion chelators, Sato \& Zannoni (1976) went on to suggest that ascorbic acid is capable of protecting the $\mathrm{Fe}^{2+}$ ion site of the cytochrome P-450 molecule. Thus, interactions with various trace elements is another potential mode of action of the vitamin.

A recent report (Holloway \& Rivers, 1981) describes investigations into the influence of chronic ascorbic acid deficiency and excessive consumption of the vitamin on hepatic microsomal cytochromes, bile acid metabolism, liver and plasma cholesterol concentration and biliary lipid secretion. Dietary extremes of ascorbic acid were found to cause similar alterations in these factors, indicating an affect of the vitamin on cholesterol metabolism similar to that reported here for drug metabolism. Holloway \& Rivers (1981) reported marked susceptibility of cholesterol-7- $\alpha$-hydroxylase (cholesterol-7- $\alpha$-monoxygenase; EC 1.14.13.17) activity to dietary extremes of ascorbic acid, which far exceeded that of either cytochrome P-450 or $b_{5}$. The work of these authors is not strictly comparable with our studies since they used deficient diets supplemented with ascorbic acid. Nevertheless, the highest dose level of $20 \mathrm{~g} / \mathrm{kg}$ diet, which is equivalent to approximately $500 \mathrm{mg} / \mathrm{d}$ per animal, is far in excess of the US National Research Council's (1978) recommendation of $200 \mathrm{mg} / \mathrm{kg}$ diet, and is of a similar order to that used in the present study, $300 \mathrm{mg} / \mathrm{d}$.

Antipyrine undergoes extensive oxidative metabolism, and a dose-related response appears to exist for its clearance from the body. Houston (1977) reported increased body clearance following treatment of human volunteers with $1 \mathrm{~g}$ ascorbic acid/d for 1 week. This result was corroborated by Wilson et al. (1976). However, these workers also demonstrated that at dose levels above $1.2 \mathrm{~g} / \mathrm{d}$ antipyrine body clearance was decreased.

The surprising ability of ascorbic acid to alter biological systems in the same way at low and high concentrations has been previously documented both in vivo and in vitro. A preliminary report by Kamath et al. (1978) described elevated serum cholesterol levels in guinea-pigs given the highest $(150$ and $300 \mathrm{mg} / \mathrm{d})$ and lowest $(0.5 \mathrm{mg} / \mathrm{d})$ amounts of the vitamin tested. Similarly, Wilbur \& Walker (1978) reported depletion of adrenal cholesterol esters in guinea-pigs given diets containing either no ascorbic acid or $20 \mathrm{~g} / \mathrm{kg}$ for 3 weeks. In vitro studies of microsomal lipid peroxidation (Caputto et al. 1961; Seregi et al. 1978) and steroidogenesis (Shimizu, 1970; Carballeria et al. 1974; Bjorkhem et al. 1978) have demonstrated a similar response to increasing ascorbic acid concentration, i.e. an initial stimulatory effect, followed by an inhibitory effect at higher concentrations.

In most of the studies, peak enzyme activity was observed at an ascorbic acid concentration of 0.5-1.0 mM, well within the normal physiological range (Holloway \& Rivers, 1981).

It should be noted that, whilst some authors have advocated the regular use of gram doses of the vitamin (Pauling, 1970; Stone, 1972), work by Kallner et al. (1979) has indicated that tissue saturation is achieved in the majority of healthy, non-smoking individuals with a dose of $100 \mathrm{mg} / \mathrm{d}$. This result would tend to suggest that unless requirements were dramatically increased due to a metabolic disturbance, the regular ingestion of gram doses of ascorbic acid is not necessary to maintain tissue saturation of the water-soluble vitamin. In addition, it has been shown by several groups of workers (Kubler \& Gehler, 1970; Kallner et al. 1977; Hornig et al. 1980) that the percentage absorption of a dose of the vitamin decreases with the size of the dose, such that a $20 \%$ absorption occurs with a $5 \mathrm{~g}$ dose, and the urinary excretion of ascorbic acid also increases with increasing dose. Indeed, the regular ingestion of gram doses of ascorbic acid can result in an adaptation to such doses (Angel et al. 1975) with the consequent increased risk of scurvy if the dosage is abruptly stopped (Cochrane, 1965; Schrauzer \& Rhead, 1973; Norkus \& Rosso, 1975). 
These results suggest that, when taken in the large doses advocated by some authors (Pauling, 1970; Stone, 1972), ascorbic acid ceases to act simply as a vitamin. Furthermore, it should be considered a drug, capable of competing for substrates and cofactors with co-administered drugs and endogenous substrates, such as cholesterol, which are metabolized through the same drug-metabolizing system.

Growing children and those groups of people on multi-drug regimens are particularly at risk, especially as doctors are not necessarily aware of a patient's regular ingestion of vitamin suplements when drugs are being prescribed.

Consequently, although previously-quoted toxic effects, such as increased risk of urinary stone formation, have been shown to be unimportant, this paper presents new evidence to suggest that large doses of ascorbic acid should not be used indiscriminantly in an attempt to improve health. Nevertheless, therapeutic use in such conditions as cancer (Cameron $e t$ al. 1979), rheumatoid arthritis (Rinehart et al. 1936) and bone disorders (Basu et al. 1978) may well be beneficial and should be considered on their own merit.

\section{REFERENCES}

Angel, J., Alfred, B., Leichter, J., Lee, M. \& Marchant, L. (1975). Int. J. Vit. Nutr. Res. 45, 237.

Basu, T. K., Smethurst, M., Gillett, M. B., Donaldson, D., Jordan, S. J., Williams, D. C. \& Hicklin, J. A. (1978). Acta Vitam. Enzymol. (Milano) 32, 45.

Bjorkhem, I., Kallner, A. \& Karlmar, K. E. (1978). J. Lipid Res. 19, 695.

Boyd, E. M. \& Taylor, F. I. (1969). Ind. Med. 38, 42.

Briggs, M. H., Garcia-Webb, P. \& Davies, P. (1973). Lancet ii, 201.

Cameron, E., Pauling, L. \& Leibovitz, B. (1979). Cancer Res, 39, 663.

Caputto, R., Trucco, R. E. \& Kitabchi, A. E. (1961). Ann. N.Y. Acad. Sci. 92, 79.

Carballeria, A., Fishman, L. M. \& Durnhofer, F. (1974). Metabolism 23, 1175.

Chatterjee, G. G. (1967). In The Vitamins, vol. 1, p. 399 [W. H. Sebrell and R. S. Harris, editors]. New York: Academic Press.

Cochrane, W. A. (1965). Can. Med. Ass. J. 93, 893.

Conney, A. H., Bray, G. A., Evans, C. \& Bruns, J. J. (1961). Ann. N.Y. Acad. Sci. 92, 115.

Degkwitz, E. \& Kim, K. S. (1973). Hoppe-Seyler's Z. Physiol. Chem. 354, 555.

Ernste, L., Siekovitz, P. \& Palade, G. E. (1962). J. Cell Biol. 15, 541.

Holloway, D. E. \& Rivers, J. M. (1981). J. Nutr. 111, 412.

Hornig, D., Vuilleumier, J.-P. \& Hartmann, D. (1980). Int. J. Vit. Nutr. Res. 50, 309.

Houston, J. B. (1977). Br. J. Clin. Pharmac. 4, 236.

Kakar, S. C., Wilson, C. W. M. \& Bell, J. N. (1975). Irish J. med. Sci. 44, 227.

Kallner, A., Hartman, D. \& Hornig, D. (1977). Int. J. Vit. Nutr. Res. 47, 383.

Kallner, A., Hartman, D. \& Hornig, D. (1979). Am. J. Clin. Nutr. 32, 530.

Kamath, S., Tang, J., Smith, A., Moy, K., Wadhwa-Mehta, S. \& Bramante, P. (1978). Fedn Proc. Fedn Am. Socs exp. Biol. 37, 589 (Abstr.).

Kato, R., Takanaka, A. \& Oshima, T. (1969). Jap. J. Pharmac. 19, 25.

Kubler, W. \& Gehler, J. (1970). Int. J. Vit. Nutr. Res. 40, 442.

Lamden, M. P. \& Chrystowski, G. A. (1954). Proc. Soc. expl. Biol. Med. 85, 190.

Leber, H., Degkwitz, E. \& Staudinger, H. (1969). Hoppe-Seyler's Z. Physiol. Chem. 350, 439.

Lowry, O. H., Rosenbrough, N. J., Farr, A. L. \& Randall, R. J. (1951). J. biol. Chem. 191, 265.

Mitch, W. E., Johnson, M. W., Kirshenbaum, J. M. \& Lopez, R. E. (1981). Clin. Pharmac. Ther. $29,318$.

National Research Council (1978). Nutrient Requirements of Laboratory Animals. Washington DC: National Academy of Sciences.

Norkus, E. P. \& Rosso, P. (1975). Ann. N.Y. Acad. Sci. 258, 401.

Omura, T. \& Sato, R. (1964). J. biol. Chem. 239, 2370.

Pauling, L. (1970). Vitamin $C$ and the Common Cold. San Francisco: W. H. Freeman \& Co.

Rikans, L. E., Smith, C. R. \& Zannoni, V. G. (1978). J. Pharmac. exp. Ther. 204, 702.

Rinehart, J. F., Greenberg, L. D. \& Baker, F. (1936). Proc. Soc. expl Biol. 35, 347.

Sato, P. H. \& Zannoni, V. G. (1974). Biochem. Pharmac. 23, 3121.

Sato, P. H. \& Zannoni, V. G. (1976). J. Pharmac. exp. Ther. 198, 295.

Schenkman, J. B., Cha, Y.-N., Moldeus, P. \& Cinti, D. L. (1973). Drug Met. Disp. 1, 516.

Schmidt, K.-H., Hagmaier, V., Hornig, D. H., Vuilleumier, J.-P. \& Rutishauser, G. (1981). Am. J. clin. Nutr. 34, 305 .

Schrauzer, G. N. \& Rhead, W. J. (1973). Int. J. Vit. Nutr. Res. 43, 201.

Seregi, A., Schaefer, A. \& Komlos, M. (1978). Experientia 34, 1056. 
Shimizu, K. (1970). Biochim. biophys. Acta 210, 333.

Stein, H. B., Hasan, A. \& Fox, I. H. (1976). Ann. int. Med. 84, 385.

Stone, I. (1972). The Healing Factor - Vitamin C Against Disease. New York: Grosset and Dunlap.

Sutton, J. L., Basu, T. K. \& Dickerson, J. W. T. (1982). Biochem. Pharmac. 31, 1591.

Wilbur, V. A. \& Walker, B. L. (1978). Lipids 13, 116.

Wilson, C. W. M. (1975). Ann. N.Y. Acad. Sci. 258, 355.

Wilson, J. T., Van Boxtel, C. J., Alvan, G. \& Sjoqvist, F. (1976). J. clin. Pharmac. 16, 265.

Zannoni, V. G., Flynn, E. J. \& Lynch, M. (1972). Biochem. Pharmac. 21, 1377. 